\title{
Fall Prevention: Lifestyle Factors and Fall Risk ${ }^{1}$
}

\author{
Linda B. Bobroff and Jennifer Hillan²
}

Many things can cause you to fall. The good news is that you can make some easy changes to decrease your risk of falling.

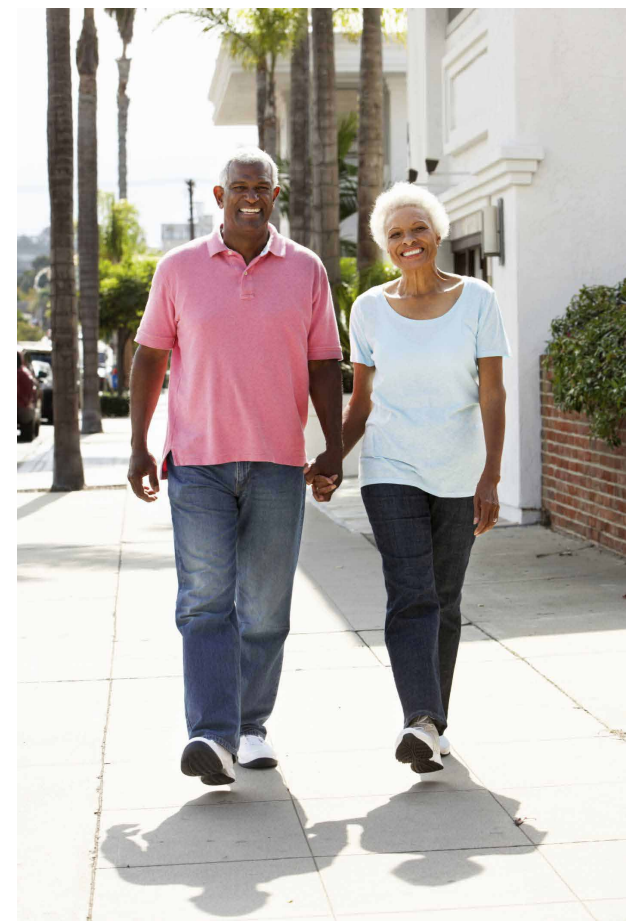

Figure 1. Regular physical activity helps to reduce fall risk. Walking is a great way to stay active.

Credits: iStock

\section{Choose Your Shoe}

It is best to avoid walking barefoot, but some shoes can make you more likely to fall. To reduce your risk of falling, do the following:

- Choose shoes with low heels and nonskid soles.

- Instead of slip-on shoes, wear shoes with laces or fabric fasteners.

- Avoid wearing high heels.

- Avoid wearing shoes with slippery soles or floppy slippers.

\section{Stay Active!}

Staying active is one of the most important things you can do for yourself! Regular activity helps keep you healthy and also can reduce your risk of falls. Physical activity improves your strength, balance, and gait (the way you walk). Walking, swimming, dancing, and

1. La versión en español de este documento es Prevención de Caídas: Estilos de Vida y Riesgo de Caídas (FCS2230-Span). This document is FCS2230, one of a series of the Department of Family, Youth and Community Sciences, UF/IFAS Extension. First published: October 2004. Latest revision: October 2013. Visit the EDIS website at http://edis.ifas.ufl.edu.

2. Linda B. Bobroff, PhD, RD, LD/N, professor, and Jennifer Hillan, MSH, RD, LD/N, former educator/trainer, Department of Family, Youth and Community Sciences, UF/IFAS Extension, Gainesville, FL 32611. 
gardening are great ways to stay active. Every day move your body and have fun!

\section{Limit or Avoid Alcohol}

Alcohol makes you less alert. It also can affect your coordination, which can increase your risk of falling. Ask your pharmacist if you need to avoid alcohol because of medications you take. Ask your health care provider if you should avoid alcohol due to a medical condition. If you do drink, limit yourself to one drink per day. One drink is 5 ounces of wine OR 12 ounces of beer OR 1 1/2 ounces of liquor.

\section{Review Your Medications}

Taking some types of medications, such as sedatives or certain anti-depressants, may make you more likely to fall. You also may be more likely to fall if you take multiple medications each day. Always take medications as prescribed. Review your medications with your health care provider regularly. Let your doctor or pharmacist know if you experience dizziness or other symptoms.

For additional information, visit:

- http://www.adsa.dshs.wa.gov/pubinfo/ falls/\#prevention

- http://www.cdc.gov/homeandrecreationalsafety/falls/adultfalls.html

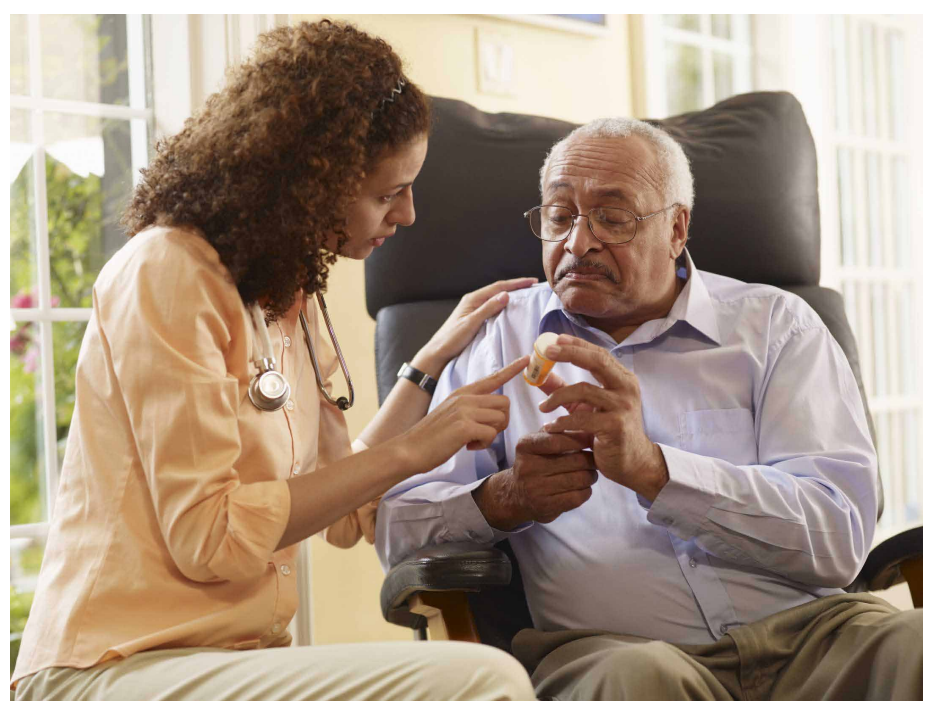

Figure 2. Check with your health care provider about possible side effects of your medications that could affect your risk of falling.

Credits: Fuse 